\title{
DRIP IRRIGATION SYSTEM USING EMBEDDED SYSTEMS: AN INITIATIVE OF SAVING WATER
}

\author{
Sneha Punia ${ }^{1}$ \\ ${ }^{1}$ M.Tech (Embedded System Designing), ITM Univeristy, Gurgaon
}

\begin{abstract}
Water is one of the basic needs of all living beings. Fresh water is less than 1\% on Earth [I] and the usage of water is increasing day by day. Agriculture practices alone requires huge amount of water. In this paper, the basic motive is to save water and prevent wastage of water by using drip irrigation technology. In Drip irrigation the water is poured just above the roots in the form of droplets. Water is given to the roots drop by drop which not only saves water but also prevents the plants from flooding and decaying due to excessive water released by irrigation methods like flood irrigation-border irrigation, furrow irrigation, check basin irrigation [II].
\end{abstract}

In this paper, microcontroller based drip irrigation method is proposed, which controls, monitors, automatically ON/OFF the water pump and gives feedback.

Drip irrigation using embedded systems is one of the most efficient techniques used to save water as well as saving time and energy of the farmers. Using embedded technology in farming practices would ease the farming and farmers will be able to keep check on the crops.

Keywords: Drip irrigation, ATmega32 microcontroller, moisture sensors, temperature sensors and GSM Module. ****

\section{INTRODUCTION}

Drip irrigation is done in two ways: manually and automatically. The system is proposed in this paper is automated using ATmega32 microcontroller, a 32-bit ATMega32A with features of $32 \mathrm{kB}$ single flash memory, $2 \mathrm{kB}$ SRAM and three 32 bit timers and 8 channel $10 \mathrm{bit}$ ADC. A solenoid valve which converts electrical energy into mechanical energy is used to ON/OFF the water flow with the help of its 2-port valve. The sensors which are placed atleast 5 feet above the roots for avoiding high moisture areas [II]. Using 10 HS coded pre-calibrated Soil Moisture Sensor of Decagon because of its low power consumption as it required $10-12 \mathrm{~mA}$ and runs with $3-15 \mathrm{~V}$ DC giving an output of $0.60-12$ Volts. This sensor could reduce $50 \%$ of the water consumption [II]. When drip irrigation is created the important parameters are temperature, humidity, carbon dioxide, ground water and light [III]. Field conditions are also necessary to be studied. The field chosen in this paper is flat areas where the field is monitored through sensors and the information is wirelessly transmitted to the base station and to GSM based mobile phone.

The whole system is divided into four essential parts: i) Base Station Unit (BSU) ii) Valve Unit (VU) iii) Sensor Unit (SU).

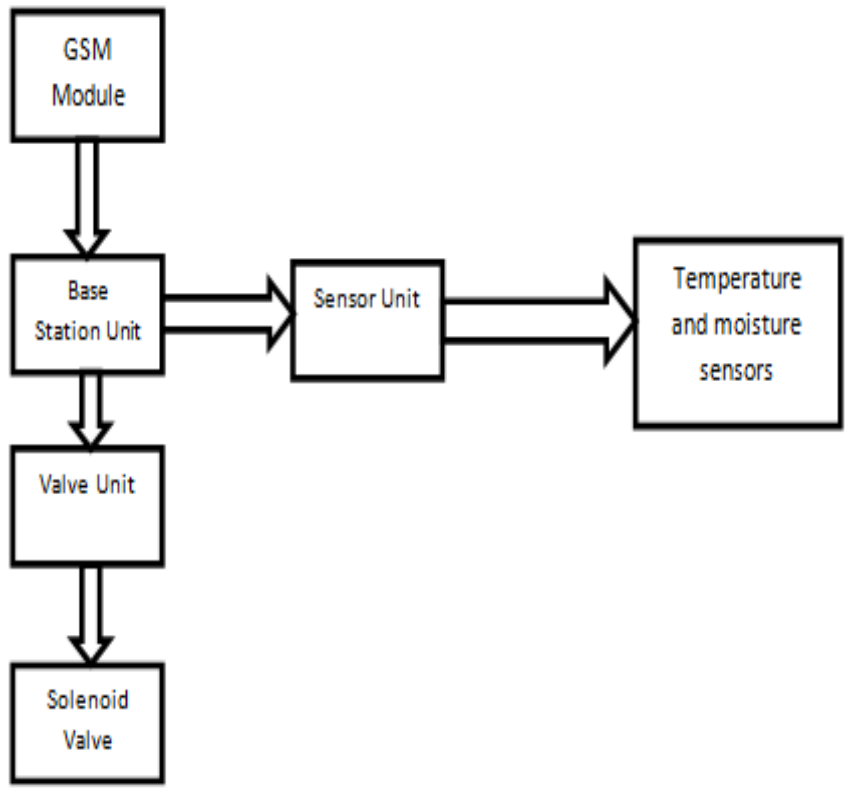

Fig 1: Basic block diagram.

\subsection{Why to Use Drip Irrigation?}

1) Weed growth is controlled

2) Soil erosion is prevented

3) Each plant gets equal amount of water

4) Save water

5) Prevention from flooding

6) Easy to install and simple to use. 


\section{DESIGN PROCESS}

The steps involved during the design process of the drip irrigation system are shown in figure 2 . Two methods can be used during the design process i.e. Top down design and Bottom up method. Top down process design is chosen in our case.

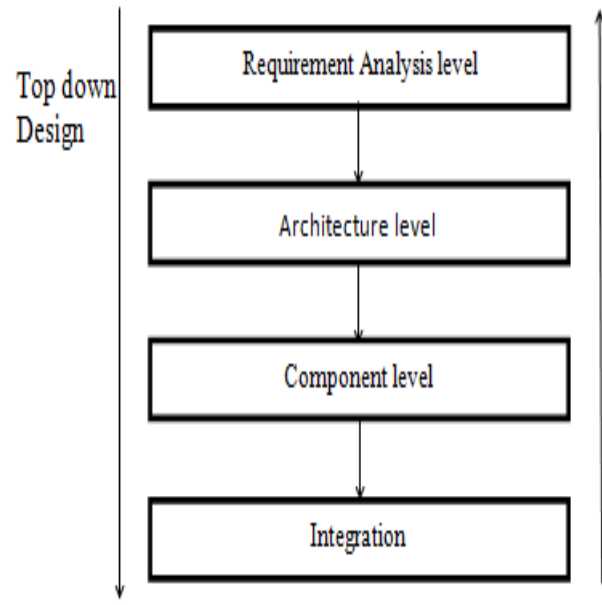

Bottom up Design

Fig 2: Design process steps using Top down design methodology.

\subsection{Requirement Analysis}

Requirement analysis is the first stage which gives a basic idea of the drip irrigation system designing process as well as the requirements needed during the implementation of the system in the field area.

Table 1: Requirements in the designing and their

\begin{tabular}{|l|l|}
\hline Requirements & Description \\
\hline Purpose & $\begin{array}{l}\text { Irrigation practices using } \\
\text { sensors and controlling } \\
\text { water level }\end{array}$ \\
\hline Input & $\begin{array}{l}\text { Temperature sensors, } \\
\text { Moisture sensors, GSM } \\
\text { module }\end{array}$ \\
\hline Output & $\begin{array}{l}\text { GSM module, LCD[16*2] } \\
\text { display, Relays, Solenoid } \\
\text { valves }\end{array}$ \\
\hline Functions & $\begin{array}{l}\text { Sensing the moisture \& } \\
\text { temperature level and } \\
\text { controlling water level }\end{array}$ \\
\hline Power & \begin{tabular}{l}
$12 \mathrm{~V}$ \\
\hline
\end{tabular} \\
\hline
\end{tabular}

\subsection{Architecture Level}

Architecture level is the second stage, consisting of the planning and the base of the drip irrigation system, giving shape to our work process of third stage i.e. component level. Architecture level mainly explains the function of i) Base Station Unit (BSU) ii) Valve Unit (VU) iii) Sensor Unit (SU) iv) GSM Module. GSM Module sends and receives the signals, sent and received from the base station. Base station is heart of the system plays an important role of medium between sensor unit and GSM module. The valve unit consists of relays and ON/OFF solenoid valves and water pump.

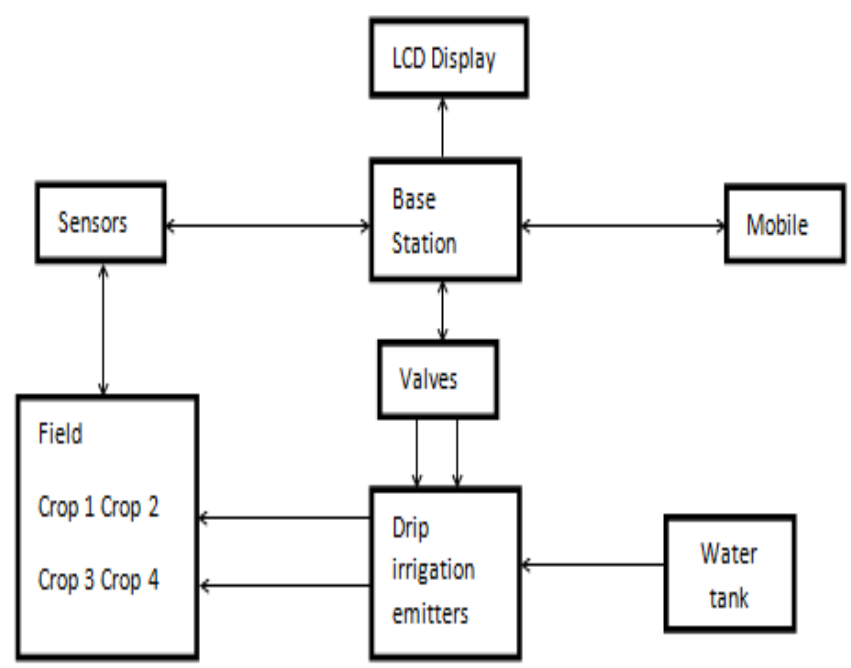

Fig 3: Preparation and planning stage of the drip irrigation system.

\subsection{Component Level}

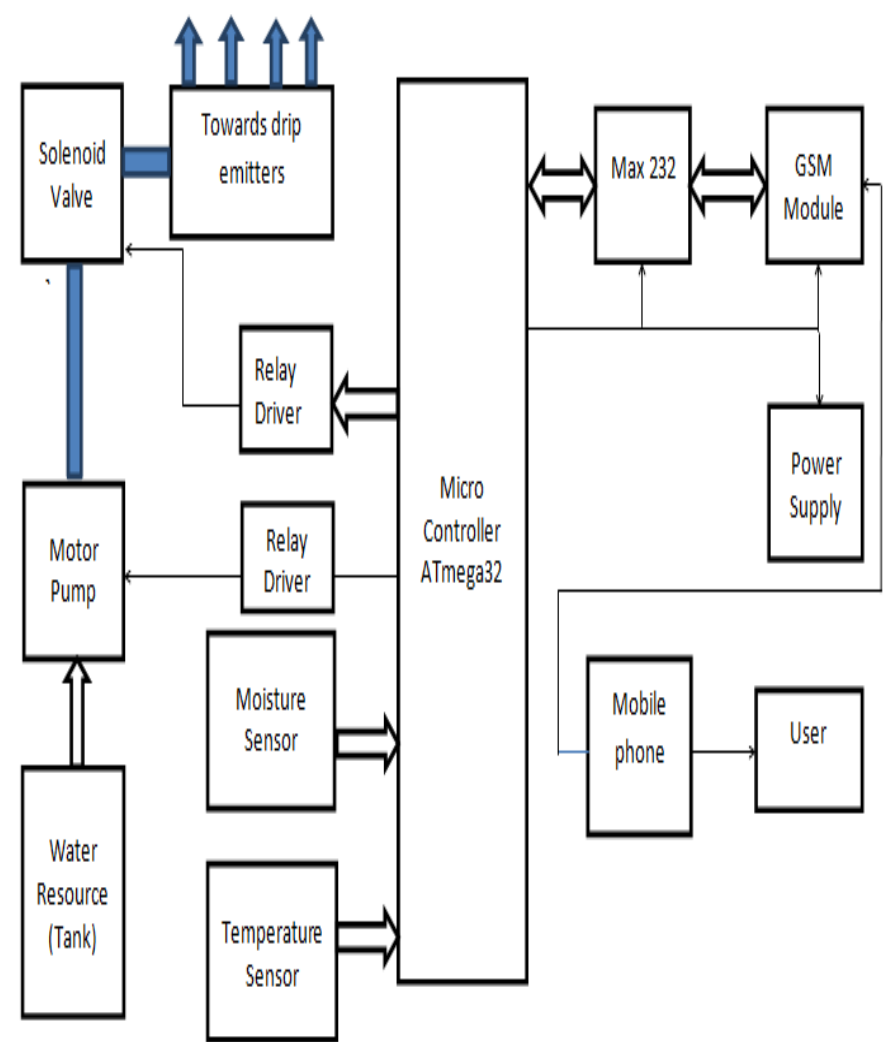

Fig 4: Components used in the drip irrigation system using embedded technology 


\subsubsection{Moisture and Temperature Sensor}

Temperature sensor used us LM35. LM35 ranges from -54 ${ }^{\circ} \mathrm{C}$ to $150{ }^{\circ} \mathrm{C}$ but our motive is to set the temperature of sensor between $25^{\circ} \mathrm{C}-35^{\circ} \mathrm{C}$. Moisture sensor $10 \mathrm{HS}$ coded pre-calibrated soil moisture sensor of Decagon which senses the moisture content present in the soil. Moisture sensor used is low power consumption and can reduce $50 \%$ of the water consumption [IV]. Whenever the temperature increases above $35{ }^{\circ} \mathrm{C}$ and the moisture of the soil lowers a message in the form of SMS (Short Message Service) is sent to the GSM module through microcontroller. The measurements of the sensors can be altered as per requirement and the type of crop in the field [V].

\subsubsection{Relay}

Relay have two main functions i) to be an intermediate between microcontroller and the solenoid valve ii) to switch ON/OFF the solenoid valve and motor pump. Whenever GSM module send SMS for switching ON the water supply the relay interfaced with microcontroller switches $\mathrm{ON}$ the solenoid valve as well as the motor pump.

\subsubsection{Solenoid Valve}

Solenoid valve is an electromechanical ON/OFF device. Solenoid valve controls the pressure and amount of water pumped into the pipes. Relay switch it ON/OFF as per requirement, the benefit of solenoid valves in drip irrigation is that they can be opened and closed depending upon the crop and the water requirement. Mix farming can also be encouraged using solenoid valves for irrigation and drip emitters over root of each crop [V].

\subsubsection{Motor Pump}

Motor pump is switched ON/OFF through relay and from the water tank the water is released towards the field. The released water passing through the pipes and drip emitters water the root of each crop plant drop by drop. Motor pump used is centrifugal pump, the most efficient water pump which has a capability to pump out water upto 200 feet [VI].

\subsection{Integration}

Integration involves two main steps: i) interfacing all the components together ii) debugging. The programming done in microcontroller (base station) is in embedded $\mathrm{C}$, in base stations debugging is foremost important. Also, controlling and setting the temperature and moisture parameter in accordance to the crops. LCD display interfaced with the base station for the readings displayed, further the readings sent to base station. Base station, compare the readings with the set parameters and then send further information to the GSM module in form of SMS. The farmer/user then with the help of SMS sends instruction to open/close valves.

\section{ADVANTAGES AND FUTURE SCOPE}

i) Saves $50 \%$ of the water that is used in flood irrigation [II].

ii) Growth of fungi, mould lessened hence the usage of harmful and strong pesticides and insecticides reduces, which reduces soil and air pollution.

iii) Weed growth reduces to almost zero, usage of weedicides gets reduced.

iv) Recently introduced in Southern-East India where water crisis is higher.

v) Scope of drip irrigation system is seen in cultivating the cash crops and other horticulture plants like cherry orchards, cardamom, viniculture etc [VIII].

\section{CONCLUSION}

In this paper we have discussed how drip irrigation would bring revolution in farming techniques. Using least amount of water, improves quality, increasing productivity of crops, making irrigation practices automatic and accurate.

\section{ACKNOWLEDGEMENTS}

I would like to thank our University and Laboratory Faculty without them this research would not be possible.

\section{REFERENCES}

[1] Maximize drip irrigation benefits by automating By Inge Bisconer, Toro Micro-Irrigation (March 12, 2008)

[2] "Controlling water use efficiency with Irrigation Automation: cases from drip and center pivot Irrigation of Corn and Soybean" Steven R. Evett, R. Troy Peters, and Terry A. Howell Southern Conservation Systems Conference, Amarillo TX, June 26-28, 200657

[3] Yandong Zhao, Jinfeng Guan, Junfu Zhang, Weilun Yin "Study on precision water-saving irrigation automatic control system by plant physiology" 978-14244-2800-7/09/2009 IEEE.

[4] Yunseop (James) Kim, member, IEEE, Robert G. Evans, and William M. Iversen "Remote sensing and control of an irrigation system using a distributed wireless sensor network" IEEE transactions on instrumentation and measurement, vol. 57, no. 7, July 2008.

[5] Dnyaneshwar Wavhal and Manish Giri "Automated Drip Irrigation Improvements Using Wireless Application", International Journal of Advance Research, IJOAR .org, Volume 1, Issue 3, March 2013, Online: ISSN 2320-9194, pp.65-73

[6] K.C. Yassine, A.H. Hammoud, M.F. Khalil, "Experimental Investigation For Centrifugal Slurry Pump Performance", Tenth International Congress of fluid Dynamics, ICFD10-EG-3061 2010.

[7] Khalid S.Rababa, "The Effect of Blades Number and Shape on the Operating Characteristics of centrifugal Pumps", European Journal of Scientific Research ISSN-1450-216X Vol. 52 No.2 (2011).

[8] Spices Board, Ministry of Commerce and Industry, Government of India, "Cultivation practices for cardamom”, January 2009. 